\title{
Tribological functionalization of titanium alloys by Micro-Arc Oxidation for marine applications
}

\author{
Aude MATHIS, Thierry MILLOT, Vincent BRANGER, Remy MULLER, Jean-Yves GUENEHEUX \\ Naval Research / CESMAN, Naval Group, BOUGUENAIS, France
}

\section{Abstract}

Micro-arc Oxidation (MAO) process is a plasma assisted electrochemical process, which allows formation of ceramic-like dry oxides on top of light alloys surfaces.

The good corrosion resistance as well as the low density of titanium alloys are recognized and so required for conception of structural parts in marine environment. However, their tribological behaviour reveals an important tendency to stick-slip phenomenon, which makes use of these alloys for dynamic contact mechanisms difficult.

Through the MAO project from IRT M2P, formation of a MAO coating composed of aluminium titanate has been investigated to improve tribological behaviour of a commercially pure titanium (Grade 2) and an $\alpha+\beta$ alloy (TA6V, Grade 5). Pin-on-disc testing has been carried out to evaluate friction coefficient and the presence or not of stick-slip phenomenon in various contact configurations (involving non-treated titanium surfaces, MAO treated surfaces, with steel or titanium balls ...) in dry or artificial seawater media. Those test campaigns are completed by evaluation of fatigue behaviour, and tribological testing on a demonstrator.

Finally, this study highlights influence of MAO coating on diminishing (to removed) stick-slip phenomenon, accompanied by a reduction of friction coefficient, whatever the kind of contact (single treated surface or both ones) and the medium.

\section{Introduction}

Titanium alloys are employed for many various applications, due to their low density and their very good corrosion resistance. However, tribological behaviour of these alloys does not alloy to use them for mechanical parts fabrication subject to friction. Indeed, seizure phenomenon is pronounced by friction between a titanium part and another mechanical part (regardless the material in contact, especially for a titanium / titanium contact).

Micro-arc oxidation (MAO) or plasma electrolytic oxidation (PEO) is an anodizing process, mainly applied to light metals and valve metals such as aluminium, titanium and magnesium. This process involving high voltage favours the growth of a thick ceramic-like oxide and allows the formation of multi-functional coatings [1-3]. Such a coating is studied here to prevent seizing and to improve tribological performance of titanium alloys by friction coefficient reduction.

Porosity of obtained coatings can be important and induce a risk of limiting adherence between oxide layers and the titanium substrate [4]. Porosities shape on coating surface is induced by electrolyte nature and impacts the coating roughness. Adherence and roughness are both determining factors for wear resistance and tribological behaviour of MAO coatings.

Friction and wear tests on MAO coatings (composed of hydroxyapatite, for biomedical application) were carried out in the literature [5] on a ball-on-disk tribometer under dry experiment conditions with an alumina ball. An interesting point of this study is the diversity of thickness, roughness and compactness of investigated MAO coatings. Compared to test results on titanium substrate without any MAO treatment, a wear significantly lower is observed, whatever the coating quality, with a minimum gain of $80 \%$ of the worn volume for the finest thickness $(30 \mu \mathrm{m})$ tested, and up to $97 \%$ of the worn volume for the most compact and smooth coating.

In the literature, tests have also been realised in fretting, with and without lubrication in order to identify impact of the environment on the tribological response of a steel ball contact on MAO treated titanium plate [6]. A significant reduction of the friction coefficient is observed under lubricated conditions with a stable coefficient equal to 0.15 , which implies a strong reduction of shear stresses at the ball-plate contact.

The main purpose of this study is to test a selection of MAO coatings under various friction conditions, to evaluate impact of test procedures and coating characteristics on the coating friction behaviour and wear resistance.

\section{Materials and experiments}

1. Materials and preparation of MAO coatings

(C) The Authors, published by EDP Sciences. This is an open access article distributed under the terms of the Creative Commons Attribution License 4.0 (http://creativecommons.org/licenses/by/4.0/). 
Commercially pure titanium grade 2 plates and $\alpha-\beta$ alloy TA6V grade 5 plates and bearings were treated by micro-arc oxidation. Micro-arc oxidation treatments were performed in order to obtain coatings mainly composed by aluminium titanate, alumina and titanium dioxide. The MAO equipment was composed of an AC power supply, an electrochemical cell as well as cooling and stirring systems. The titanium substrate was used at the anode and the electrolyte was maintained at a temperature below $30^{\circ} \mathrm{C}$. Two different current densities (10 and 30 A.dm-2) were applied in order to compare by friction testing the impact of thickness and surface roughness on tribological performance.

\section{Microstructure, thickness and chemical composition characterization of the coatings}

Thickness of coatings was measured by micrograph observations and cross-sectional morphologies were analysed by scanning electron microscope. X-ray diffraction was used to verify the presence of aluminium titanate, alumina, and titanium dioxide. Roughness was determined by using an interferometric profilometer.

\section{Ball-on-disk testing}

The friction and wear tests were carried out at room temperature on the coatings by using a ball-on-disk tribometer (TBR Anton Paar) under dry and lubricated experiment conditions. Artificial sea water (A3 type) was used as lubricant. The tribometer, presented on Figure 1, was employed using the alternative linear module and the circular module. Parameters used for each configuration linear and circular friction, are presented in Table 1.
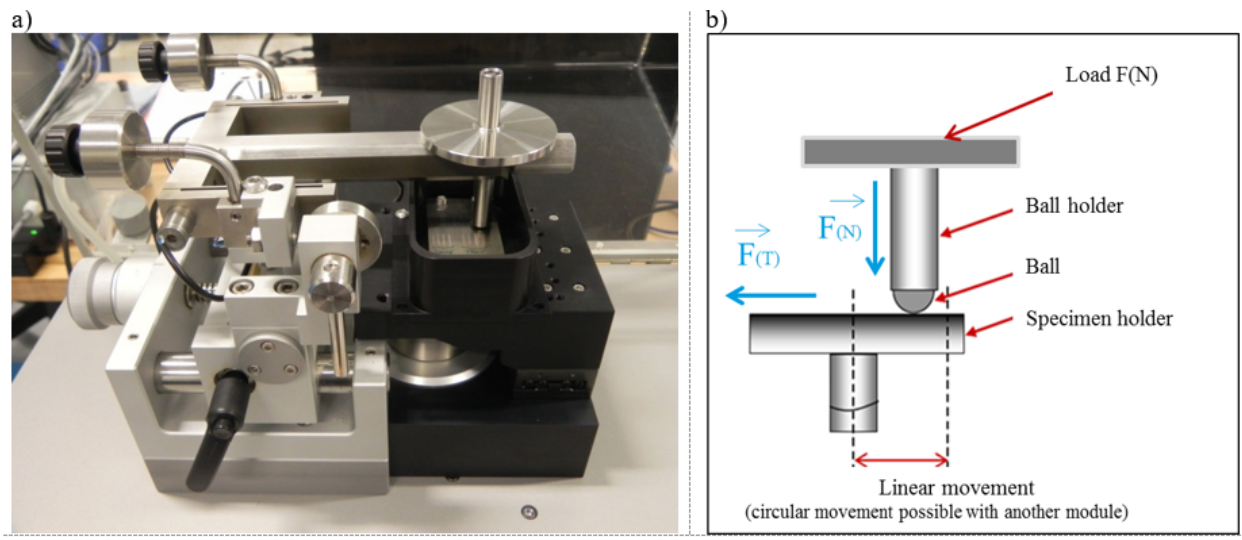

Figure 1 TBR Anton Paar tribometer (a) and schematic diagram for ball-on-disk testing

Table 1 Ball-on-disk testing parameters

\begin{tabular}{|c|c|c|}
\hline & Linear friction & Circular friction \\
\hline Tested substrates & $\begin{array}{l}\text { Grade } 2 \text { with and without MAO coating } \\
\text { Grade } 5 \text { with and without MAO coating }\end{array}$ & $\begin{array}{l}\text { Grade } 5 \text { with and without MAO } \\
\text { coating }\end{array}$ \\
\hline Load & $1 \mathrm{~N}$ & $2 \mathrm{~N}$ \\
\hline $\begin{array}{c}\text { Ball } \\
\text { (diameter : } 6 \mathrm{~mm})\end{array}$ & $\begin{array}{c}100 \mathrm{Cr} 6 \text { steel } \\
\text { or } \\
\text { titanium (grade } 2 \text { or grade } 5 \text { depending on the } \\
\text { substrate nature of the plate to test) }\end{array}$ & $\begin{array}{l}\text { Titanium grade } 5 \text { with or without } \\
\text { MAO coating }\left(10 \mathrm{~A} \mathrm{dm}^{-2}\right)\end{array}$ \\
\hline $\begin{array}{c}\text { Frequency / } \\
\text { Rotating speed }\end{array}$ & $2 \mathrm{~Hz}$ & $0,025 \mathrm{~m} \cdot \mathrm{s}^{-1} / 0,01 \mathrm{~m} \cdot \mathrm{s}^{-1} / 0,5 \mathrm{~m} \cdot \mathrm{s}^{-1}$ \\
\hline Cycles number & $500 / 1000 / 2000 / 5000$ cycles & $1000 / 5000 / 10000$ cycles \\
\hline Amplitude & $\begin{array}{l}\text { Large displacement }(+/-2.5 \mathrm{~mm}) \\
\text { or } \\
\text { Fretting (low displacement }+/-200 \mu \mathrm{m})\end{array}$ & - \\
\hline $\begin{array}{l}\text { Dry / lubricated } \\
\text { conditions }\end{array}$ & Dry or lubricated conditions & Lubricated conditions only \\
\hline
\end{tabular}

\section{Dedicated tribological test bed for shaft-bearing contact}

A technological tribometer was set up specifically to simulate friction of bearings around a shaft for large angular range (about $225^{\circ}$ ). Such a contact is quite representative of friction conditions for marine 
applications. Figure 1 presents the test bed, dedicated to this study. Some stress can be applied trough the crank to the shaft - bearing contact, as presented by Figure $1 \mathrm{~b}$.
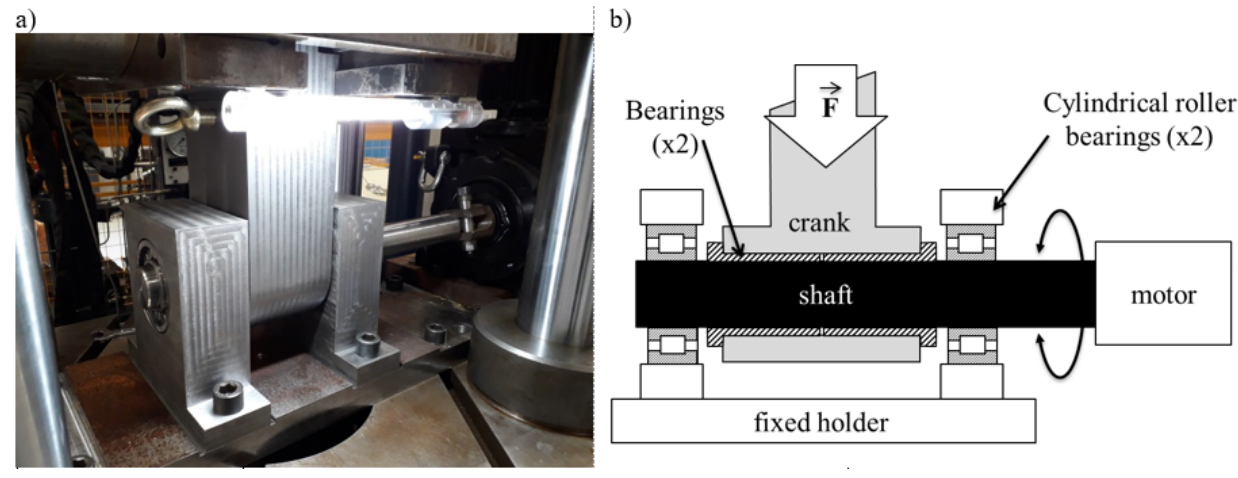

Figure 2 Experimental set-up to test friction behaviour of a shaft-bearing contact: (a) photograph of the set up and (b) schematic

The dimensions of the shaft with the bearings are $50 \mathrm{~mm}$ (diameter) and $130 \mathrm{~mm}$ (length). The tests were performed at room temperature. The range of the static load is $1 \mathrm{kN}$ to $30 \mathrm{kN}$ and the alternative movement of the shaft is done with a maximum speed of $7.5 \mathrm{r} / \mathrm{min}$.

\section{Results and discussion}

1. MAO coating characteristics: thickness and roughness

Characteristics of obtained MAO coatings on commercially pure titanium and titanium alloy T-A6V are summed up in Table 2.

Table 2 Thicknesses and roughnesses of MAO coatings obtained on Grade 2 and 5 titanium alloys

\begin{tabular}{|l|l|l|}
\hline \multicolumn{1}{|l|}{} & Thickness & Roughness Sa \\
\hline Non-treated Ti Grade 2 substrate & - & $0,3 \mu \mathrm{m}$ \\
\hline MAO coating on Ti Grade 2 at 30 A.dm-2 & $18-43 \mu \mathrm{m}$ & $3,9 \mu \mathrm{m}$ \\
\hline Non-treated Ti Grade 5 substrate & - & $0,8 \mu \mathrm{m}$ \\
\hline MAO coating on Ti Grade 5 at $10 \mathrm{~A} \cdot \mathrm{dm}^{-2}$ & $5-13 \mu \mathrm{m}$ & $1,7 \mu \mathrm{m}$ \\
\hline MAO coating on Ti Grade 5 at 30 A.dm-2 & $13-50 \mu \mathrm{m}$ & $5,3 \mu \mathrm{m}$ \\
\hline
\end{tabular}

Coatings obtained on Grade 2 titanium with a current density of 10 A.dm-2 were not really conclusive in terms of thickness and oxide composition ( $\mathrm{TiO} 2$ only); micro-arcs were barely observed on top of the substrate surface during MAO process.

Globally, MAO coatings obtained at $30 \mathrm{~A} . \mathrm{dm}-2$ provide a rougher surface and a thicker oxide layer than those obtained at lower current density (10 A.dm-2).

\section{Linear ball-on-disk test results on Grade 2 titanium substrate with and without MAO coating}

For large ball-on-disk displacements under dry conditions, measured friction coefficients obtained after 5000 cycles present a decrease of $50 \%$ for the contact "Grade 2 (ball) - Grade 2 with MAO (disk)" compared to the contact "Grade 2 (ball) - Grade 2 (disk)" without any MAO coating. Friction coefficient of the mixed contact is stable from 1000 cycles at the value of 0.13 . Seizing phenomenon is also well reduced by presence of MAO coating.

For fretting tests under dry conditions, previous gain observed on seizing phenomenon as well as friction coefficient reduction is not so significant between a "titanium - titanium" contact and a "titanium - MAO" contact. 
has been realised for large displacements, on Grade 5 substrate with and without MAO coating under dry conditions. Evolution of friction coefficient in each configuration is represented on Figure 2.
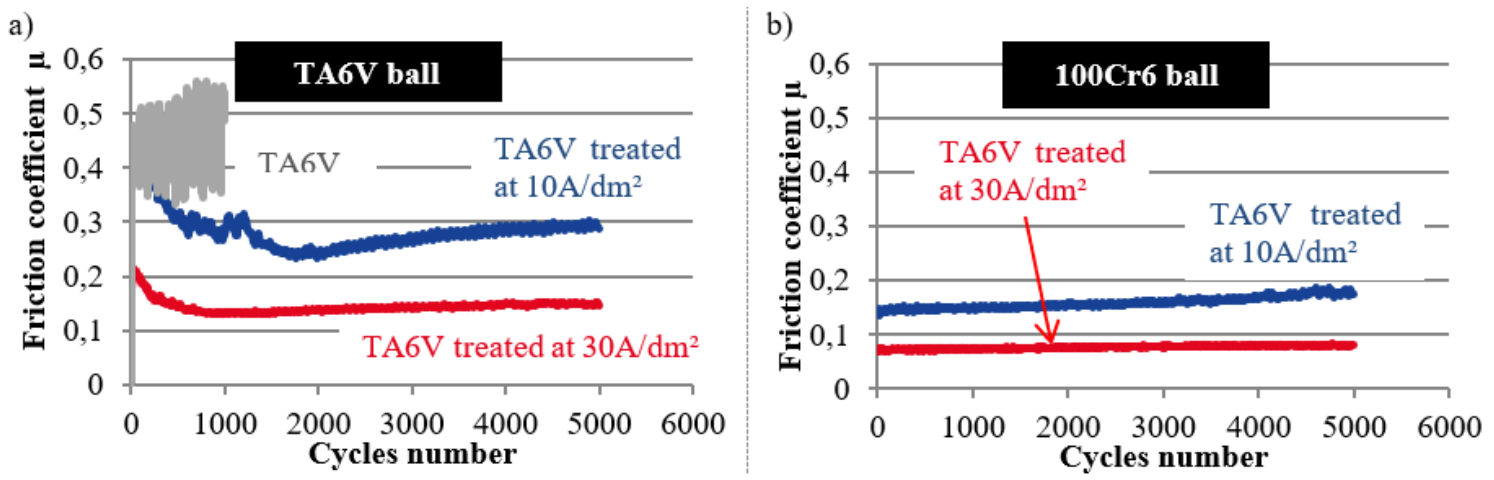

Figure 3 Evolution of friction during reciprocating tests on titanium Grade 5 with and without MAO treatment with a) titanium ball and b) steel ball

The "reference state" of a titanium - titanium contact (oscillating curve at about 0,45 of friction coefficient on Figure 2a) presents a very high friction coefficient, as well as a strong tendency for seizure due to the large variations of friction coefficient for a low cycle number. Regardless the current density used to coat Grade 5 titanium substrate (10 or 30 A.dm-2), seizure is practically suppressed and friction coefficient is significantly reduced. MAO coating obtained at 30 A.dm-2 allows to reach lower levels of friction coefficient than those obtained at $10 \mathrm{~A} . \mathrm{dm}-2$. Consequently, surface roughness increase does not look to impact tribological behaviour during large displacements. With the $100 \mathrm{Cr} 6$ steel ball (see Figure $2 \mathrm{~b}$ ), a stable tribological behaviour is reached from the early cycles, contrarily to the contact with titanium ball which requires an accommodation of surfaces on the first 1000 to 2000 cycles. Moreover, friction coefficient is lower than with the contact with titanium ball.

Tests in fretting carried out in a similar configuration as previously for Figure 2a (with titanium ball), have been done to establish a comparison of the tribological behaviour of TA6V with and without MAO treatment in large displacements and fretting. Results are presented in Figure 3.

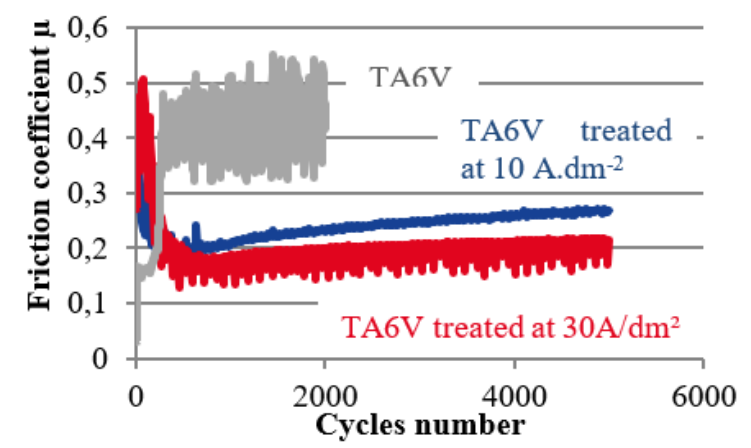

\section{Figure 4 Evolution of friction in a fretting mode on MAO treated and non-treated titanium Grade 5 with titanium ball contact}

According to Figure 3, MAO treatment induces a friction coefficient reduction, with the same tendency as observed in large displacement: MAO treatment carried out at $30 \mathrm{~A} . \mathrm{dm}-2$ leads to a lower friction coefficient than for MAO coating formed at 10 A.dm-2. However, variations observed at $30 \mathrm{~A} . \mathrm{dm}-2$ are more pronounced than at $10 \mathrm{~A} . \mathrm{dm}-2$. This traduces a tendency to seizure easier for contact with the thickest and roughest coating in fretting. It is so possible to suppose that increase of surface roughness impacts and sensibly deteriorates the seizing behaviour of the MAO coating. Following this hypothesis, it can also be 
supposed that the ceramic nature of MAO coating explains the intensity of seizure phenomenon does not reach intensity of its observed on non-treated TA6V, although roughness is much higher.

Linear ball-on-disk tests carried out in both large displacements and fretting conditions provide similar results under dry and lubricated (artificial sea water A3) conditions. Compared to non-treated titanium Grade 5 substrate, MAO coatings provide a better friction contact with a lower friction coefficient and a reduced (or even suppressed) seizure.

\section{Circular ball-on-disk test results on Grade 5 titanium substrate with and without MAO coating}

Circular ball-on-disk tests have been carried out under lubricated conditions (simulated sea water A3). Regardless test configuration, presence or not of a MAO coating on top of titanium Grade5 surface does not impact the value of friction coefficient. Seizure phenomenon does not change regarding the type of contact as well (non-treated titanium on MAO coating or both MAO coated surfaces, etc.). However, wear tracks and worn volumes differ quite a lot as a function of the kind of surfaces in contact, as shown by Figure 4.

Wear tendency observed on balls is equal to that for disks: MAO coating applied on one of the surface or on both of them drastically limits wear with an asymptotic behaviour reached at about 5000 cycles for heterogeneous contact. Equivalent limitation of wear is observed for the other different speeds tested in this study, although worn volume is more important for highest speed on both ball and disk surfaces.

a)

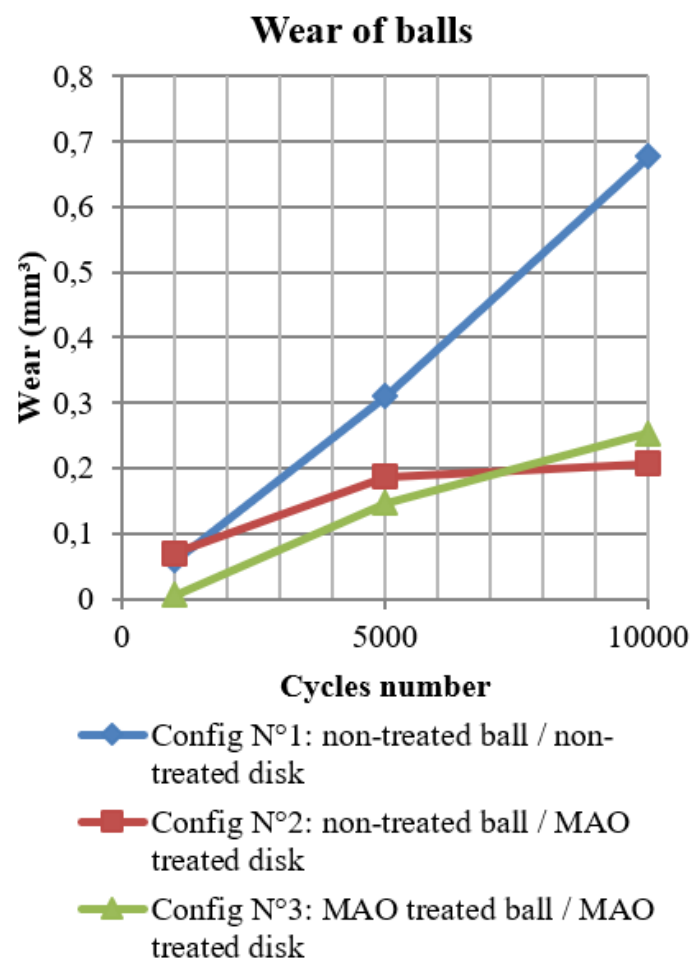

b)

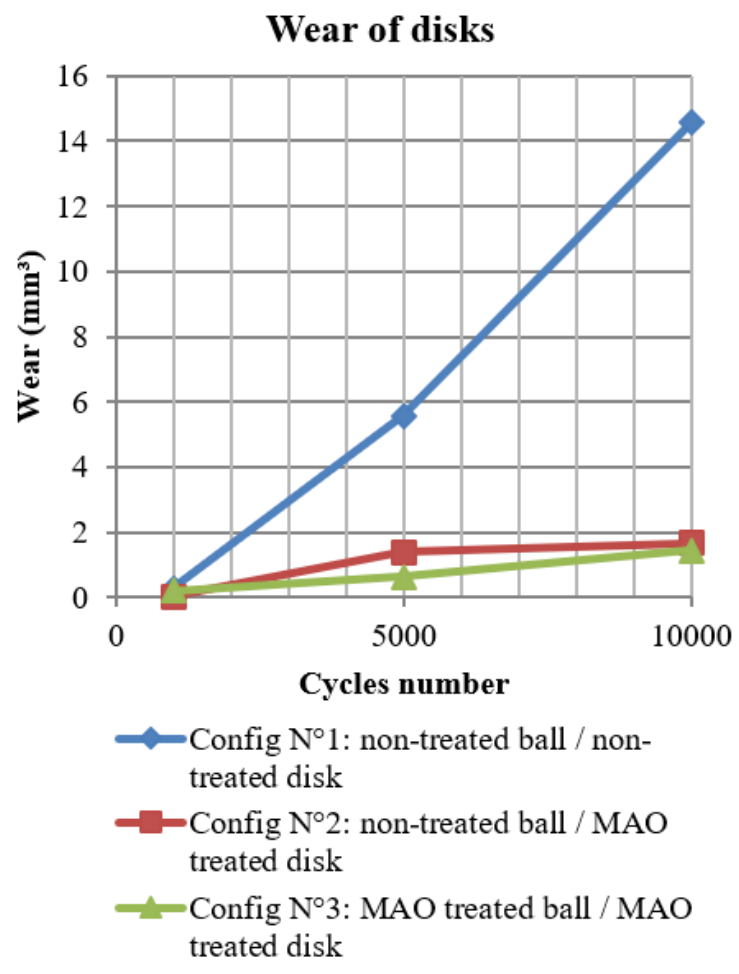

Figure 5 Wear curves on balls (a) and on disks (b) after circular ball-on-disk tests at a speed of 0,025 m.s-1

5. Shaft-bearing friction test results on Grade 5 titanium substrate with and without MAO coating Tribological testing using dedicated test bed for representative shaft-bearing contact has been carried out to qualitatively apprehend advantages of MAO coatings on titanium Grade 5 friction parts under dry conditions. In order to have a reference state, non-treated titanium shaft and bearings have been tested on low cycles, until seizure appearance. Figure 5 presents both shaft and bearing surfaces after such a test, which highlights seizing effect of galling after only 50 cycles under a load of $30 \mathrm{kN}$. 

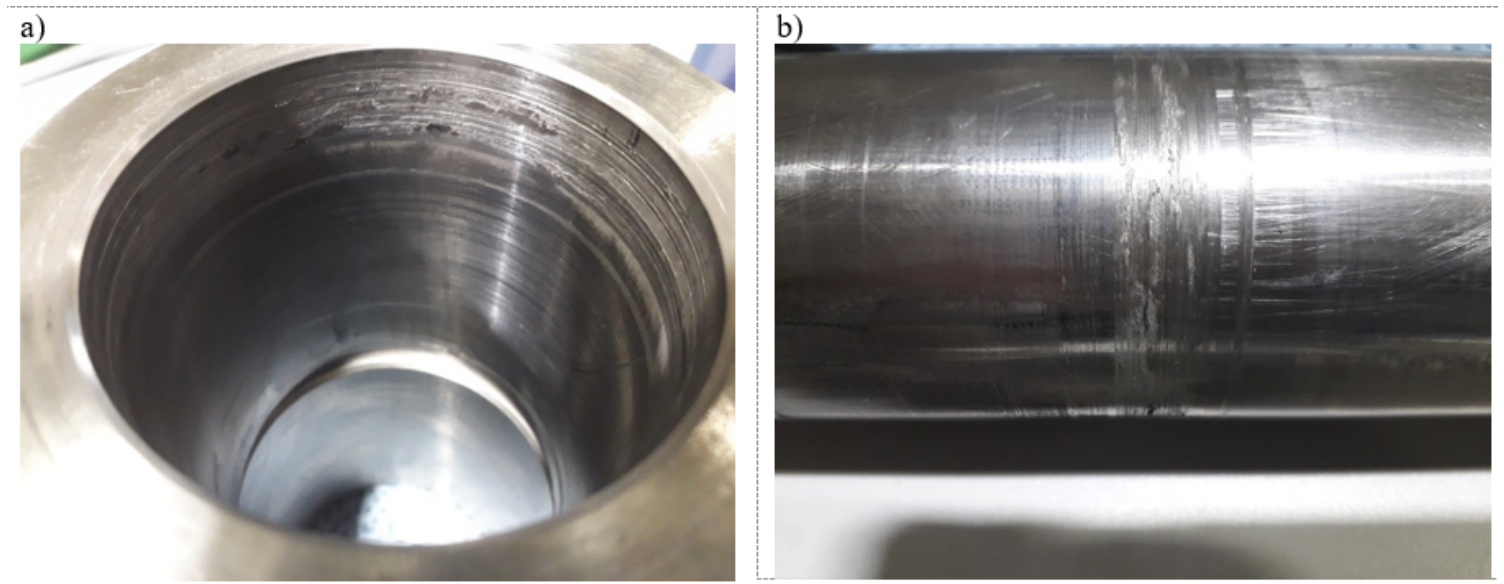

Figure 6 (a) Bearing and (b) shaft after tribological testing ( 50 cycles and under $30 \mathrm{kN}$ ) on dedicated test bed, with both titanium Grade 5 surfaces without any MAO treatment: important seizing phenomenon appears

Tests have been realised with MAO treated bearings at 10 and $30 \mathrm{~A} . \mathrm{dm}-2$, for 100 cycles and different loads $(1 \mathrm{kN}$ and $30 \mathrm{kN})$. Under $30 \mathrm{kN}$, MAO coating obtained at $10 \mathrm{~A} \cdot \mathrm{dm}-2$ is not enough thick and its wear appears rapidly until seizure at 100 cycles. However, MAO coating obtained at 30 A.dm-2 reaches 100 cycles without any seizure effect. By diminishing applied load to $1 \mathrm{kN}$, shaft-bearing contact is less load ; MAO coating obtained at 10 A.dm- 2 presents a better friction behaviour than under $30 \mathrm{kN}$ and one of both bearing is totally intact. This can be due to a defect in balancing load application, as suggested by photograph on Figure 6. However, even on the most worn surface of the bearing, seizure is not detected; the shaft surface remains intact after 100 cycles.

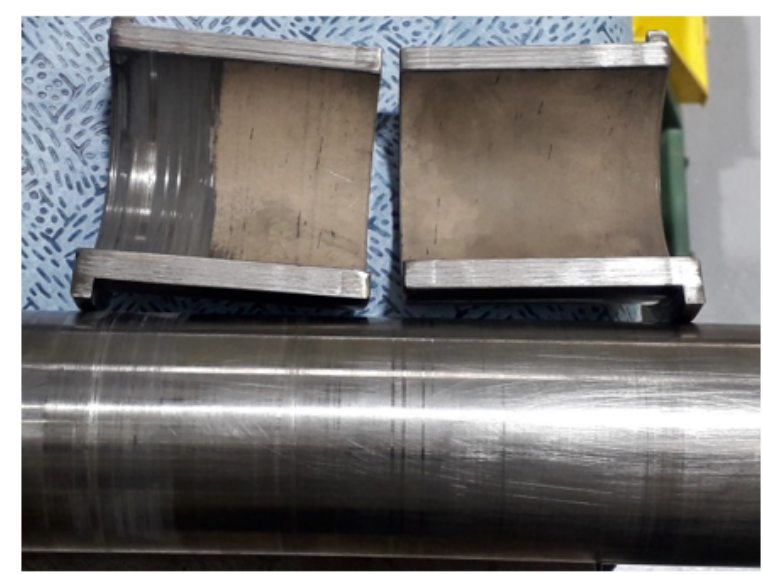

Figure 7 MAO treated bearings and non-treated shaft after tribological testing (100 cycles under $1 \mathrm{kN})$ on dedicated test bed: no seizing phenomenon but only localised wear of the MAO coating on one of both bearings

\section{Conclusion}

In this study, different kinds of friction contact have been investigated through linear and circular ball-ondisk and shaft-bearing like contact testing.

Linear friction tests realised on large displacements and on fretting provide promising results to reduce friction coefficient and to suppress seizure phenomenon. Current density used to coat titanium surface by MAO process pilots oxide thickness and surface roughness. For the highest current density tested, friction coefficient results on large displacement are better than that for lower current density. Tendency is reversed 
for fretting where surface roughness has a more prominent role. For circular ball-on-disk tests, MAO coating is all the more interesting to reduce wear that rotating speed is low, considering worn volumes on the ball as well as on the disk.

Concerning shaft-bearing tribological testing, first qualitative tests carried out in this study highlight a promising increase of the galling resistance of the material, especially regarding the relatively low tested coating thickness. In the future and to optimise this tribological test bed, balancing of applied load shall be controlled and instrumentation shall be put in place to measure friction coefficient and temperature increase during testing.

\section{Acknowledgements}

We would like to thank all partners of the "MAO project" for their technical support and for providing us MAO treated specimens to test, and more specifically Institut de Recherche Technologique Matériaux Métalliques et Procédés (IRT M2P), Galvanoplastie Industrielle Toulousaine (GIT) and Laboratoire d'Etude des Microstructures et de Mécanique des Matériaux (LEM3).

\section{References}

[1] S. Ikonopisov, Theory of electrical breakdown during formation of barrier anodic films, Electrochimica Acta, Volume 22, Issue 10, 1977, pages 1077-1082.

[2] A.L. Yerokhin, A. Leyland, A. Matthews, Kinetic aspects of aluminium titanate layer formation on titanium alloys by plasma electrolytic oxidation, Applied Surface Science, Volume 200, Issues 1-4, 2002, pages 172-184.

[3] A. Mathis, E. Rocca, D. Veys-Renaux, J. Tardelli, Electrochemical behaviour of titanium in KOH at high potential, Electrochimica Acta, Volume 202, 2016, pages 253-261.

[4] A.L. Yerokhin, X. Nie, A. Leyland, A. Matthews, Characterisation of oxide films produced by plasma electrolytic oxidation of a Ti-6Al-4V alloy, Surface and Coatings Technology, Volume 130, Issue 2, 2000, pages 195-206.

[5] S. Durdu, \& M. Usta, The tribological properties of bioceramic coatings produced on Ti6Al4V alloy by plasma electrolytic oxidation. Ceramics International, Volume 40, Issue 2, 2014, pages 3627-3635.

[6] Y. Wang, T. Lei, L. Guo, \& B. Jiang, Fretting wear behavior of microarc oxidation coatings formed on titanium alloy against steel in unlubrication and oil lubrication. Applied surface science, Volume 252, Issue 23, 2016, pages 8113-8120. 